\title{
Genetic Associations Between Personality Traits and Lifetime Reproductive Success in Humans
}

\section{Berg, Venla}

2016-11

Berg , V , Lummaa , V , Rickard , I J , Silventoinen, K, Kaprio , J \& Jokela , M 2016 , ' Genetic Associations Between Personality Traits and Lifetime Reproductive Success in Humans ' , Behavior Genetics , vol. 46 , no. 6 , pp. 742-753 . https://doi.org/10.1007/s10519-016-9803-5

http://hdl.handle.net/10138/230028

https://doi.org/10.1007/s10519-016-9803-5

publishedVersion

Downloaded from Helda, University of Helsinki institutional repository.

This is an electronic reprint of the original article.

This reprint may differ from the original in pagination and typographic detail.

Please cite the original version. 


\title{
Genetic Associations Between Personality Traits and Lifetime Reproductive Success in Humans
}

\author{
Venla Berg ${ }^{1,7}$ (D) Virpi Lummaa ${ }^{2}$ Ian J. Rickard ${ }^{3} \cdot$ Karri Silventoinen $^{4}$. \\ Jaakko Kaprio $^{5,6} \cdot$ Markus Jokela $^{1}$
}

Received: 1 October 2015/Accepted: 27 July 2016/Published online: 9 August 2016

(C) Springer Science+Business Media New York 2016

\begin{abstract}
Personality has been associated with reproductive success in humans and other animals, suggesting potential evolutionary selection pressures. However, studies to date have only examined these associations on a phenotypic level, which may be inadequate in estimating evolutionary change. Using a large longitudinal twin dataset of contemporary Finns, we compared the phenotypic (breeder's equation) and genetically informed (the Robertson-Price identity) associations between lifetime reproductive success (LRS) and two personality traitsneuroticism and extraversion. Neuroticism was not associated with LRS at the phenotypic nor genetic level, while extraversion was associated with higher LRS in men both phenotypically and genetically. Compared to the univariate phenotypic analysis, the genetic analysis suggested a larger selection response of extraversion, and a selection response
\end{abstract}

Edited by Eric Turkheimer.

Venla Berg

venla.berg@vaestoliitto.fi

1 Institute of Behavioural Sciences, University of Helsinki, Helsinki, Finland

2 Department of Biology, University of Turku, Turku, Finland

3 Department of Anthropology, University of Durham, Durham, UK

4 Department of Social Research, University of Helsinki, Helsinki, Finland

5 Department of Public Health, University of Helsinki, Helsinki, Finland

6 Institute for Molecular Medicine Finland FIMM, Helsinki, Finland

7 Present Address: Population Research Institute, Väestöliitto, P.O. Box 849, 00101 Helsinki, Finland of neuroticism due to indirect selection. We estimated that neuroticism decreases by .05 standard deviations and extraversion increases by .11 standard deviations by one generation. Our results highlight the importance of considering genetic associations between personality and fitness and investigating several inter-related personality traits and their covariance with each other to predict responses to selection more accurately.

Keywords Personality - Twins · Fitness - Reproductive success $\cdot$ Natural selection $\cdot$ Breeder's equation

\section{Introduction}

The concept of personality refers to individual variation in behavioral and emotional tendencies that are relatively stable across situations and over time. Personality has been studied in humans for decades, and recently, personality in other animals has also garnered attention (Gosling 2001). Personality variation is partly genetic, with the broad sense heritability being around $40 \%$ in humans (Vukasovic and Bratko 2015). The heritability of personality in other animals has been studied less but heritability estimates between 20 and $60 \%$ have been reported (van Oers et al. 2005), with a trend towards higher heritability in more benign environments (Charmantier and Garant 2005).

With the advent of personality research on non-human animals, focus has turned into the functions and evolutionary origins of personality (e.g., Dingemanse and Wolf 2010; Penke et al. 2007; Sih et al. 2004). When heavily simplified, Fisher's fundamental theorem of natural selection (Fisher 1930) is usually interpreted as natural selection depleting genetic variation, leaving only the form associated with the greatest evolutionary fitness (Falconer and 
Mackay 1996; Merilä and Sheldon 1999). Hence, several theories on the evolution and maintenance of heritable variation in personality have been proposed. These theories rely heavily on the fitness consequences of personality. Thus far studies on the evolution of personality have been based on the so called "phenotypic gambit": the notion that observed phenotypic fitness associations correspond to underlying genetic patterns in a way that warrants evolutionary conclusions (van Oers and Sinn 2011). Concurrently, it is becoming increasingly clear that the phenotypic approach to evolution, selection, and predicting selection responses may be inadequate (e.g., Merilä et al. 2001a; Morrissey et al. 2010). Our aim is to examine whether the phenotypic gambit is justified when considering the evolution of personality.

On the phenotypic level, higher extraversion and related traits, such as higher sociability and activity are associated with higher reproductive rates in humans (Alvergne et al. 2010a; Berg et al. 2013, 2014; Dijkstra and Barelds 2009; Jokela et al. 2011; Jokela and Keltikangas-Järvinen 2009; Jokela et al. 2009). Traits related to emotional reactivity and stress sensitivity, such as higher neuroticism and higher harm avoidance are, in turn, associated with lower reproductive rates (Jokela et al. 2009, 2011; Reis et al. 2011). These associations, however, seem to vary between studies, with some finding no associations (e.g., Eaves et al. 1990; Nettle 2005) or associations contrasting the ones described here (e.g., Alvergne et al. 2010a; Jokela et al. 2010). In addition, associations between personality variation and different fitness components have been reported in many non-human animals as well (Smith and Blumstein 2008). Thus, personality could be under selection in many species across the phylogeny, making the evolutionary viewpoint of personality even more crucial.

A number of possible mechanisms maintaining genetic variation in personality have been proposed. Firstly, mutations constantly introduce genetic variation into the genetic pool of a population. A majority of mutations are deleterious, because they randomly interfere with the adaptive, evolved genetic material (Eyre-Walker and Keightley 2007). Mutation-selection balance refers to situations where one end of a personality trait continuum would be the adaptive optimum, corrupted by deleterious mutations, with natural selection working to clear this deleterious genetic variation out of the genetic pool (see e.g., Penke et al. 2007). In this scenario, one end of the personality trait continuum would be consistently associated with higher fitness across all situations and populations. Balancing selection, on the other hand, refers to mechanisms that actively work to maintain genetic variation. For example, stabilizing selection maintains genetic variation by favoring intermediate levels, and disruptive selection by favoring both extremes of a personality trait continuum, so that the associations between personality and fitness would be non-linear (Eaves et al. 1990). Another example of balancing selection is differential selection in fluctuating environments, where one end of a personality trait continuum is associated with higher fitness in some environmental conditions but detrimental to fitness in other environmental conditions (see e.g., Dingemanse et al. 2004). And in frequency dependent selection, the fitness consequences of a personality trait depend on the frequency of the trait in the population (see e.g., Wolf and McNamara 2012).

Environmental changes can also introduce genetic variation in behavioral traits. For example, societal changes in the twentieth century seem to have increased the role of individual differences in reproductive behavior, making features such as age at first attempt to get pregnant and number of children, heritable (Briley et al. 2015; Kohler et al. 1999). Other related behaviors, such as fertility motivation or the desired number of children have also proven to be genetically influenced in contemporary humans (Miller et al. 2010). In a pre-industrial Finnish population (Pettay et al. 2005), fertility was heritable in women but not in men. The society was characterized by strict social monogamy, and male fecundity was primarily constrained by the fecundity of his spouse, which may explain the lack of heritability in men (Pettay et al. 2005). Contemporary Western societies, in contrast, provide ample opportunities for individual behavioral differences, such as personality, to influence reproductive outcomes. Interestingly, simultaneously with the increased heritability in fertility during the twentieth century, the Five Factor Model personality traits conscientiousness and openness to experience have become more important fertility predictors (Jokela 2012). Modern environments are therefore ideal to examine the fitness consequences, genetics and (micro) evolution of personality.

To date, the theoretical accounts on the evolution of personality have usually started from the premises that personality is under natural selection and that the phenotypically observed natural selection induces evolutionary responses in personality (e.g., Dingemanse and Réale 2005; Dingemanse and Wolf 2010). However, natural selection observed at the phenotypic level has no evolutionary consequences unless the trait correlates genetically with fitness (Van Tienderen and De Jong 1994). Especially in wild populations, where environmental influences affect phenotypes, the underlying genetic associations between a trait and fitness may not correspond to the phenotypic associations (Morrissey et al. 2010). This poses a problem for evolutionary theory and predictions.

The traditional way to predict the selection response, that is, the change in population mean across two generations, is based on the breeder's equation (Morrissey et al. 
2010). According to the breeder's equation, the selection response equals the product of the trait's heritability and phenotypic selection differential. Selection differential is the phenotypic covariance between the trait and relative fitness (Falconer and Mackay 1996, see "Materials and methods" section for details). In controlled conditions with little environmental variation, genetic differences are likely to be manifested on the phenotypic level, so that selection for phenotypes correlates with genotypes as predicted by the breeder's equation (Hill 2014). In wild populations, this rarely seems to be the case, and there are several examples with no selection response despite an apparent directional selection for a heritable trait (Merilä et al. 2001b).

Possible reasons for the breeder's equation to fail to predict selection responses correctly are manifold. Firstly, if two traits are genetically correlated, selection pressures on one trait may induce evolutionary change in the other (Dochtermann and Roff 2010). A multivariate form of the breeder's equation (see "Materials and methods" section for details) can incorporate more complex information on genetic correlations between multiple traits, which improves the prediction of selection response (Lande and Arnold 1983). Secondly, and even more importantly, the breeder's equation yields unbiased estimates only if the phenotypic selection differential reflects a causal association between the trait and fitness (Morrissey et al. 2010). In other words, the estimates of selection responses may be biased by confounding factors.

For example, a study on wild red deer (Cervus elaphus) (Kruuk et al. 2002) found antler size to be both heritable and phenotypically associated with fitness, yet there was no evolution on antler size during the 30-year study period. Nutritional status and other environmental factors may have influenced both antler size and fitness, thus creating a spurious selection differential for antler size. Similarly, in passerine birds (Ficedula albicollis) the condition of fledglings was both heritable and positively associated with fitness, but the average phenotypic condition still decreased rather than increased during the 20-year study period (Merilä et al. 2001a). The fledglings' condition was selected for at the genetic level, and average genetic condition did indeed increase over time. However, this genetic change was probably concealed by simultaneously deteriorating environmental conditions, i.e., reducing food supply (Merilä et al. 2001a).

An alternative way of predicting microevolution is the Robertson-Price identity, or the secondary theorem of natural selection, according to which the selection response equals the additive genetic covariance between the trait of interest and relative fitness (Falconer and Mackay 1996; Morrissey et al. 2010, see "Materials and methods" section for details). This equation is less sensitive to environmental confounding factors that may bias the breeder's equation
(Morrissey et al. 2010; Rausher 1992). The RobertsonPrice identity is biased only if genetic confounders are omitted from the model (Rausher 1992).

In the present study, we investigated whether the expected selection response in personality based on the breeder's equation is qualitatively similar to the expected selection response based on the genetically informed Robertson-Price identity. We used a large twin sample which included measurements of extraversion and neuroticism. Fitness was defined as the number of children born alive to participants, i.e., lifetime reproductive success (LRS). Extraversion describes how joyous, sociable, talkative, and outgoing a person is, whereas neuroticism describes how easily a person feels negative feelings, becomes nervous or is sensitive to stress. Extraversion and neuroticism are the two personality dimensions most reliably associated with reproductive behaviors in humans (Penke and Jokela 2016), and they are included in most models of human and animal personality (Bouchard and Loehlin 2001).

\section{Materials and methods}

\section{Participants}

The data were derived from the Finnish Twin Cohort Study. In 1974, all Finnish twin pairs of the same sex born before 1958 with both co-twins alive in $1975(\mathrm{~N}=13,888)$ were identified from the Population Register Centre of Finland (Kaprio and Koskenvuo 2002). In 1975, a questionnaire concentrating on genetic and environmental origins of complex diseases was mailed to these twins (response rate $89 \%)$. Extraversion and neuroticism were also assessed in this questionnaire (Rose et al. 1988b). The present sample consisted of individuals born in 1950-1957, for whom data on live births were available. After excluding 488 persons due to missing data on zygosity, the final sample for the phenotypic analyses included 7669 individuals (1378 monozygotic (MZ) females, $1101 \mathrm{MZ}$ males, 2647 dizygotic (DZ) females, and 2543 DZ males). For the genetic twin modelling, only data on twin pairs with complete personality data from both members of the pair were used (513 excluded pairs), resulting in $661 \mathrm{MZ}$ female pairs, $511 \mathrm{MZ}$ male pairs, 1247 DZ female pairs, and 1159 DZ male pairs (altogether 7156 individuals). The exclusion of individuals whose cotwin's personality data was missing from the twin modelling sample had little effect on sample statistics (Table 1). For the cohorts born in the 1950s in Finland, the total fertility rate is around 1.9, the mean age at first marriage around 25 for men and 23 for women, and age at first birth around 25-29 for women (Pitkänen and Jalovaara 2007, Ruokolainen and Notkola 2007). The descriptive statistics of the final sample are presented in Table 1. 
Table 1 Descriptive statistics

\begin{tabular}{llllll}
\hline & \multicolumn{2}{l}{ Women } & & & Men \\
\cline { 2 - 3 } \cline { 6 - 7 } & Mean & SD & & Mean & SD \\
\hline Neuroticism & 1.51 & .24 & & 1.40 & .25 \\
Extraversion & 1.47 & .27 & & 1.52 & .27 \\
Number of children in 1975 & .27 & .57 & .14 & .41 \\
Total number of children & 1.74 & 1.27 & & 1.67 & 1.33 \\
Age in 1975 & 21.27 & 2.26 & & 21.43 & 2.26 \\
$\mathrm{~N}$ & 4025 & & & 3644 & \\
\hline
\end{tabular}

Total number of children is top-coded at 6 for 6 or more children $S D$ standard deviation

\section{Measures}

Zygosity was assessed in the 1975 questionnaire with questions about the similarity of appearance of a twin pair at an early school age. This standard procedure used to determine zygosity in twin studies has been shown to have high validity against genetic markers in the present sample (Sarna et al. 1978). In 1975, the twins' personality was also assessed using a short form of the Eysenck Personality Inventory (Eysenck 1967; Floderus 1974; Rose et al. 1988b). Questions concerning "your typical ways of feeling and acting" related to extraversion (nine items, see Appendix 1) and neuroticism (ten items, see Appendix 1) were answered on a dichotomous yes/no scale. Mean scores for the scales were calculated if no more than two items in the scale were missing. The Cronbach's alpha reliability was .73 for extraversion and .74 for neuroticism, indicating good internal consistency for the personality measures. Women were, on average, higher on neuroticism than men, whereas men were higher on extraversion (Table 1).

Comprehensive information on live births from January 1950 until June 2009 from the Finnish population register was linked to the participants using a unique personal identification number assigned to each Finnish citizen. By 2009, participants were 51-59 years of age and the reproductive age of women and vast majority of men was passed (there were no births in women after 2003 and only one birth in men in 2009), and we therefore have an accurate and exhaustive measure of LRS. LRS has also been shown to be a good estimate of long-term fitness in modern societies (Goodman and Koupil 2009), and it is the theoretically correct measure to be used in quantitative genetic studies of evolutionary selection (Wolf and Wade 2001). Due to paternal uncertainty, underestimation of children born to men is possible. However, this is unlikely to have affected the results severely, as the proportion of children without a known biological father in Finland during the late twentieth century was only around $2 \%$ (Kartiovaara and Säkkinen 2007).
The overall cohort study was approved by the Ministry of Social Affairs and Health, and has since been approved by the data protection ombudsman. After complete description of the study to the participants, written informed consent was obtained. The linking of the birth data was provided and approved by Population Register Centre. The Finnish legislation does not require ethical approval for linking such information to existing datasets. The present analysis did not require additional institutional review board approval because it was a secondary data analysis of existing and anonymized data.

\section{Statistical analysis}

For the purposes of our analyses, LRS was converted into relative fitness, i.e., individual's number of children relative to the mean number of children in the population (in this case, the study sample; Falconer and Mackay 1996). Relative fitness, hereafter denoted by $w$, was the outcome variable in all our analyses. Because there were few individuals $(.5 \%)$ with more than six children we top-coded the number of children at six. $21 \%$ of women and $29 \%$ of men remained childless until the end of the study period, a slightly higher percentage than the national average for the period (Ruokolainen and Notkola 2007). Parenthood and having children can influence the development of personality (Jokela et al. 2009). From the present sample, a total of 1418 participants, $22 \%$ of women and $12 \%$ of men, had at least one child by 1975 . Personality assessed in 1975 was therefore adjusted for number of children born prior to that, in order to account for the possible issues of reverse causality. Personality was also adjusted for the participant's age at the personality measurement: we first conducted regressions of neuroticism and extraversion on these two covariates, and used the regressed variables in all subsequent analyses. Data analyses were carried out with Stata 13.0 and Mplus 7.0 statistical software packages.

\section{Phenotypic analysis}

We first examined the phenotypic relations between both personality traits and $w$ by regression models of $w$ on personality. Possible differences in the studied associations between men and women were examined by entering interaction terms of neuroticism and sex and extraversion and sex in the model. In the case of a significant interaction term, the final model was conducted for men and women separately. Also, we tested for possible non-linear associations between the personality traits and $w$ with regression models having personality quartiles as independent variables and with quadratic personality traits as independent variables. As there were no signs of marked non-linear associations between the two personality traits and $w$, all 
subsequent analyses were performed with linear modelling. We took account of the correlated nature of the data (both two twins from the same family contributing to the results) by using robust variance estimation for cluster-correlated data (Williams 2000) in all phenotypic regression models.

\section{Genetic analysis}

We then investigated the genetic and environmental (co)variance structure within and between the variables with standard biometrical twin modelling (Neale and Maes 2003), in which the observed phenotypic variance of a variable was decomposed into latent genetic (A), shared environmental (C), and unique environmental (E) parts. We first conducted univariate biometrical models separately for each personality trait and $w$ to determine the best fitting models. This was done to investigate which of the factors, A, C, and E, contributed significantly to the variance of each variable. Nested models were compared by examining the change in $\chi^{2}$ values and AIC and BIC indices, describing the model fit, between different models. If the change in model $\chi^{2}$ values is not statistically significant, the more parsimonious model is preferred because then the fit of the more parsimonious model is not significantly poorer, and it explains the data with fewer parameters.

We then extended the analyses into a multivariate model to examine whether the covariance between neuroticism, extraversion and $w$ is mediated through environmental or genetic pathways. A trivariate Cholesky decomposition parametrisation model (which simply restates the (co)variance structure of the variables in terms of environmental and genetic effects) was used to attain the genetic and environmental covariance matrices, $\mathrm{G}$ and $\mathrm{E}$, for neuroticism, extraversion, and $w$ (Neale and Maes 2003).

All twin models were estimated by maximum likelihood method, and the means were not used in the estimation. The distribution of $w$ was grossly non-normal. The parameter estimates created by structural equation modelling in general are robust against non-normality, but the null hypothesis might be rejected too easily (Kline 2005). Case-bootstrapping (500 draws; Efron and Tibshirani 1993) was therefore used to attain reliable standard errors.

\section{Selection responses}

Finally, we calculated the expected selection responses of neuroticism and extraversion using the univariate and multivariate breeder's equations and the Robertson-Price identity. The univariate breeder's equation is the crudest estimate of the selection response, but also the most readily available. Many studies using phenotypic data may have some estimates of the heritability of the studied traits at hand, but not necessarily information concerning the genetic correlations between the studied traits (see e.g., Jokela et al. 2010). The multivariate breeder's equation makes the estimates of the selection responses more precise by taking into account other causal factors between the trait studied and fitness, but requires genetic information that is more difficult to attain (Morrissey et al. 2010). Further, even the multivariate form of the breeder's equation will yield biased estimates if any factors (be it individual characteristics or environmental influences) correlating with both the measured trait and fitness are omitted (Morrissey et al. 2010; Rausher 1992). The RobertsonPrice identity requires information about the genetic covariance between the studied traits and fitness-estimates that are difficult to attain (Morrissey et al. 2010). The selection response estimated with the Robertson-Price identity, however, is more precise, because it only yields biased estimates if factors that correlate genetically with both the trait of interest and fitness are omitted from the equation (Rausher 1992).

According to the univariate breeder's equation, the expected selection response, i.e., the expected change in the mean of the character between two generations $\left(\mathrm{R}_{\mathrm{y}}\right)$, of a character $(y)$ that is phenotypically associated with fitness is

$R_{y}=h_{y}^{2} S$,

where $\mathrm{h}^{2}$ is the heritability of the character (y), and $\mathrm{S}$ is the selection differential. $\mathrm{S}$ equals $\beta_{\mathrm{y}} * \sigma_{\mathrm{p}}^{2}(\mathrm{y})$ (phenotypic variance of y) (Lande and Arnold 1983). For calculating the selection responses, we used the regression coefficients $\left(\beta_{N}\right.$ and $\left.\beta_{E}\right)$ from the univariate linear regressions of relative fitness on neuroticism $(\mathrm{N})$ and extraversion (E) (Models 1 in Table 2), and the heritability estimates from the univariate twin models.

The multivariate form of the breeder's equation is

$R=\mathrm{G} \beta$,

where $\mathrm{R}$ is a vector of expected selection responses of the characters, $\mathrm{G}$ is the genetic variance-covariance matrix of the characters, and $\beta$ is a vector of partial regression coefficients of relative fitness on the characters (Lande and Arnold 1983). For calculating the selection responses, we used the partial regression coefficients $\left(\beta_{N}\right.$ and $\left.\beta_{E}\right)$ from the multivariate linear regressions of relative fitness on neuroticism (N) and extraversion (E) (Models 2 in Table 2), and the $\mathrm{G}$ matrix attained from the multivariate twin model.

According to the Robertson-Price identity, the expected selection response $\left(\mathrm{R}_{\mathrm{y}}\right)$ of a character $(\mathrm{y})$ that is associated with fitness is

$R_{y}=\sigma_{a}(y, w)$,

where $\sigma_{\mathrm{a}}(\mathrm{y}, \mathrm{w})$ is the (additive) genetic covariance between 
Table 2 Phenotypic regression models of relative fitness on personality

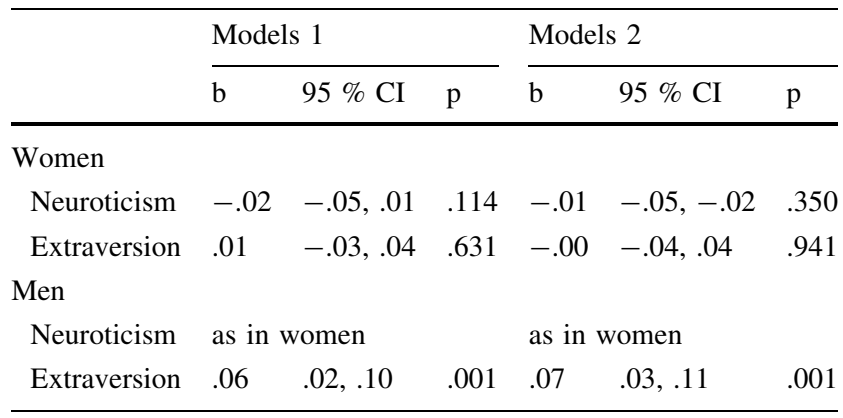

Neuroticism and extraversion are adjusted for age and number of children at 1975, and additionally for sex in models where men and women are modelled together. Sex differences were significant for extraversion, but not for neuroticism in models 1 and 2

Models 1 separate regressions on $\mathrm{N}$ and E, Model $2 \mathrm{~N}$ and $\mathrm{E}$ entered simultaneously, $C I$ confidence interval

$\mathrm{y}$ and relative fitness, $w$ (Morrissey et al. 2010). For calculating the selection responses, we used the genetic covariances between extraversion and $w$ and neuroticism and $w$ attained from the multivariate twin model. The correlated response to selection $\left(\mathrm{CR}_{\mathrm{Z}}\right)$ of a quantitative character ( $\mathrm{z})$ that is genetically correlated with a selected character (y) is

$C R_{z}=\frac{\sigma_{a}(y, z)}{\sigma_{a}^{2}(y)} \times R_{y}$,

where $\sigma_{\mathrm{a}}(\mathrm{y}, \mathrm{z})$ is the (additive) genetic covariance between $\mathrm{y}$ and $\mathrm{z}$, and $\sigma_{\mathrm{a}}^{2}$ is the (additive) genetic variance (Falconer and Mackay 1996, p. 317). For calculating the correlated selection response of neuroticism, we used the genetic covariance between the two personality traits and extraversion's genetic variance attained from the multivariate twin model, and the selection response of extraversion calculated on the basis of the Robertson-Price identity.

All the selection responses were calculated separately for men and women, where appropriate (i.e., when statistical testing showed significant differences in the associations between personality traits and $w$ between the sexes). In the last stage of calculating the selection responses in all three approaches, the attained selection responses of extraversion and neuroticism for men and women $\left(\mathrm{R}_{\mathrm{Em}}\right.$, $\mathrm{R}_{\mathrm{Nm}}$ and $\mathrm{R}_{\mathrm{Ef}}, \mathrm{R}_{\mathrm{Nf}}$ respectively) were summed up to attain the total selection responses of neuroticism $\left(\mathrm{R}_{\mathrm{N}}\right)$ and extraversion $\left(\mathrm{R}_{\mathrm{E}}\right)$ (Falconer and Mackay 1996, p. 191):

$R_{N}=\frac{1}{2} R_{N f}+\frac{1}{2} R_{N m}$, and

$R_{E}=\frac{1}{2} R_{E m}+\frac{1}{2} R_{E f}$
Finally, for illustrative purposes (since personality traits have no real metrics), the expected selection responses were converted into standardized units by dividing the attained selection responses of neuroticism and extraversion by their respective phenotypic standard deviations.

\section{Results}

\section{Phenotypic analysis}

We first examined the phenotypic associations between personality traits and $w$. Sex differences in the associations between personality and $w$ were tested by entering interaction terms of personality by sex, as well as main effects of personality, in the regression models. The univariate regressions of $w$ on neuroticism and extraversion showed a significant sex difference for extraversion (for the interaction term, $\mathrm{b}=.05, \mathrm{p}=.041$ ), but not for neuroticism $(\mathrm{b}=.04, \mathrm{p}=.189)$. Taking these interaction results into account, there was no association between neuroticism and $w$ in women or in men, and a positive association between extraversion and $w$ in men but not in women (Model 1 in Table 2). There was a moderate negative correlation between neuroticism and extraversion in women $(\mathrm{r}=-.26, \mathrm{p}<.0001)$ and men $(\mathrm{r}=-.29, \mathrm{p}<.0001)$. Therefore, linear regressions of relative fitness on personality with the two traits entered simultaneously were run, to examine their independent effects and to attain partial selection differentials for the multivariate breeder's equation. The interaction between extraversion and sex $(\mathrm{b}=.07, \mathrm{p}=.014)$ indicated sex differences in the multivariate associations, while the interaction between neuroticism and sex did not $(b=.06, p=.055)$. The final phenotypic models, performed separately for men and women for extraversion, indicated no associations between neuroticism and $w$, and a positive phenotypic association between extraversion and $w$ in men (Model 2 in Table 2).

\section{Univariate genetic analysis}

The results from the univariate twin models indicated substantial heritability for all the three traits in both sexes, as has been reported earlier for neuroticism and extraversion in this twin cohort (Rose et al. 1988a): between 39 and $54 \%$ of the variation in these traits was explained by underlying genetic variation (Table 3). As in numerous previous studies on the factors underlying personality variation (Vukasovic and Bratko 2015), and different components of fitness especially in contemporary populations (Kohler et al. 2006; Kosova et al. 2010), the estimated effects of shared environment (C) were zero or close to 
zero and not statistically significant in all three variables. The AE-models fit the data equally well as the ACEmodels in all three variables (comparison of the nested models yielded $\chi^{2}(2)=.00, \mathrm{p} \approx 1.00$ for neuroticism, $\chi^{2}(2)=.00, \mathrm{p} \approx 1.00$ for extraversion, and $\chi^{2}(2)=.42$, $\mathrm{p}=.809$ for $w)$. The shared environmental components were therefore omitted from the final univariate models (Models 2) and subsequent multivariate models. In the final univariate models, models in which parameter estimates were allowed to differ for men and women fit significantly better than models with parameters constrained to be equal for both sexes (comparison of the nested models yielded $\chi^{2}(2)=13.74, \mathrm{p}=.001$ for neuroticism, $\chi^{2}(2)=7.35$, $\mathrm{p}=.025$ for extraversion, and $\chi^{2}(2)=9.47, \mathrm{p}=.009$ for $w)$. The sex-differentiated models were also better for all three variables on the basis of AIC (but not BIC; data not shown), suggesting sex differences in the variance structures of both personality traits and $w$.

\section{Multivariate genetic analysis}

We then extended the above genetic analysis into a trivariate twin model to investigate the covariance structure of the two personality traits and $w$. The difference between sexes in the covariance structure of the variables was statistically significant based on the Chi square test $\left(\chi^{2}(12)=45.75, \mathrm{p}<.001\right)$ as well as the AIC $(115,403.27$ for the sex-constrained model, 102,267.57 for the sex-differentiated model) and BIC (115,477.47 for the sex-constrained model, 102,415.96 for the sex-differentiated model). The genetic and environmental variances and covariances calculated from the best fitting trivariate model are shown in Table 4. In women, there were no genetic or environmental covariances between either of the personality traits and $w$. In men, there was a positive genetic covariance, but no environmental covariance, between extraversion and $w$, and no genetic or environmental covariances between neuroticism and $w$. In addition, in both men and women, there was a negative genetic and a negative environmental covariance between neuroticism and extraversion.

\section{Comparison of the expected selection responses}

In the final stage of our analyses, we calculated the expected selection responses from the phenotypic and genetic analyses, using the univariate and multivariate breeder's equations, and the Robertson-Price equation. The results of these calculations are depicted in Fig. 1. All three equations yielded similar results in terms of the direction of selection response for both personality traits (with the exception of the univariate breeder's equation which predicted no selection response for neuroticism). The magnitude of the predicted selection responses, however, varied substantially according to the equation used. For neuroticism, the point estimate of the selection response based on the Robertson-Price identity was almost three times larger than that based on the multivariate breeder's equation. According to the univariate breeder's equation, there would be no expected selection response for neuroticism at all. For extraversion, the point estimates from the univariate and multivariate breeder's equations were almost identical, while the expected selection response based on the Robertson-Price identity was almost three times larger. In terms of standard deviations, based on the Robertson-Price identity, the next generation is expected to be .05 standard deviations less neurotic, and .11 standard deviations more extraverted than the studied generation.

\section{Discussion}

The present findings from a large, longitudinal twin study suggest that two personality traits, neuroticism and extraversion, could be expected to evolve in this contemporary industrialized society. The average neuroticism is

Table 3 Proportions of variance (95\% confidence intervals) from univariate models

\begin{tabular}{|c|c|c|c|c|c|}
\hline & \multicolumn{3}{|l|}{ Model 1} & \multicolumn{2}{|l|}{ Model 2} \\
\hline & $\mathrm{A}(\%)$ & $\mathrm{C}(\%)$ & $\mathrm{E}(\%)$ & A $(\%)$ & $\mathrm{E}(\%)$ \\
\hline \multicolumn{6}{|l|}{ Women } \\
\hline Neuroticism & $53.2(46.8,59.6)$ & $.0(-2.8,2.8)$ & $46.8(41.4,52.2)$ & $53.2(47.9,58.5)$ & $46.8(41.5,52.1)$ \\
\hline Extraversion & $53.5(47.9,59.1)$ & $.0(.0, .0)$ & $46.5(40.9,52.1)$ & $53.5(47.9,59.1)$ & $46.5(40.9,52.1)$ \\
\hline$w$ & $33.9(19.0,48.9)$ & $4.0(-6.8,14.8)$ & $62.1(55.4,68.7)$ & $38.9(33.1,44.8)$ & $61.1(55.2,66.9)$ \\
\hline \multicolumn{6}{|l|}{ Men } \\
\hline Neuroticism & $52.0(41.7,62.4)$ & $.0(-6.6,6.6)$ & $48.0(41.8,54.1)$ & $52.0(46.2,57.8)$ & $48.0(42.2,53.8)$ \\
\hline Extraversion & $42.7(36.2,49.3)$ & $.0(.0, .0)$ & $57.3(50.7,63.8)$ & $42.7(36.2,49.3)$ & $57.3(50.7,63.8)$ \\
\hline$w$ & $38.9(31.0,46.8)$ & $.0(-2.2,2.2)$ & $61.1(53.8,68.3)$ & $38.9(31.8,46.1)$ & $61.1(53.9,68.2)$ \\
\hline
\end{tabular}

$A$ genetic variance, $C$ shared environmental variance, $E$ unique environmental variance and measurement error 
Table 4 Genetic and environmental variances of and covariances between extraversion $(\mathrm{E})$, neuroticism $(\mathrm{N})$, and relative fitness $(w)$

\begin{tabular}{|c|c|c|c|}
\hline & (Co)variance & $95 \%$ confidence interval & $\mathrm{p}$ \\
\hline \multicolumn{4}{|l|}{ Women } \\
\hline \multicolumn{4}{|l|}{ Genetic } \\
\hline $\mathrm{N}$ & 2.99 & $2.63,3.35$ & \\
\hline $\mathrm{E}$ & 4.04 & $3.57,4.51$ & \\
\hline $\mathrm{w}$ & 3.51 & $2.92,4.10$ & \\
\hline $\mathrm{N}-\mathrm{E}$ & -.95 & $-1.25,-.65$ & .000 \\
\hline $\mathrm{N}-w$ & -.23 & $-.53, .07$ & .135 \\
\hline $\mathrm{E}-w$ & -.03 & $-.37, .31$ & .859 \\
\hline \multicolumn{4}{|c|}{ Environmental } \\
\hline $\mathrm{N}$ & 2.63 & $2.36,2.91$ & \\
\hline $\mathrm{E}$ & 3.52 & $3.11,3.93$ & \\
\hline $\mathrm{w}$ & 5.50 & $4.94,6.05$ & \\
\hline $\mathrm{N}-\mathrm{E}$ & -.71 & $-.95,-.47$ & .000 \\
\hline $\mathrm{N}-w$ & -.04 & $-.29, .21$ & .752 \\
\hline $\mathrm{E}-w$ & .11 & $-.15, .37$ & .399 \\
\hline \multicolumn{4}{|l|}{ Men } \\
\hline \multicolumn{4}{|l|}{ Genetic } \\
\hline $\mathrm{N}$ & 3.31 & $2.90,3.73$ & \\
\hline $\mathrm{E}$ & 3.12 & $2.60,3.63$ & \\
\hline $\mathrm{w}$ & 3.91 & $3.13,4.69$ & \\
\hline $\mathrm{N}-\mathrm{E}$ & -1.20 & $-1.56,-.84$ & .000 \\
\hline $\mathrm{N}-w$ & .12 & $-.24, .48$ & .507 \\
\hline $\mathrm{E}-w$ & .59 & $.18,1.00$ & .005 \\
\hline \multicolumn{4}{|c|}{ Environmental } \\
\hline $\mathrm{N}$ & 3.03 & $2.67,3.39$ & \\
\hline $\mathrm{E}$ & 4.10 & $3.65,4.56$ & \\
\hline $\mathrm{w}$ & 6.08 & $5.36,6.79$ & \\
\hline $\mathrm{N}-\mathrm{E}$ & -.74 & $-1.04,-.44$ & .000 \\
\hline $\mathrm{N}-w$ & -.11 & $-.40, .18$ & .446 \\
\hline $\mathrm{E}-w$ & -.10 & $-.46, .26$ & .573 \\
\hline
\end{tabular}

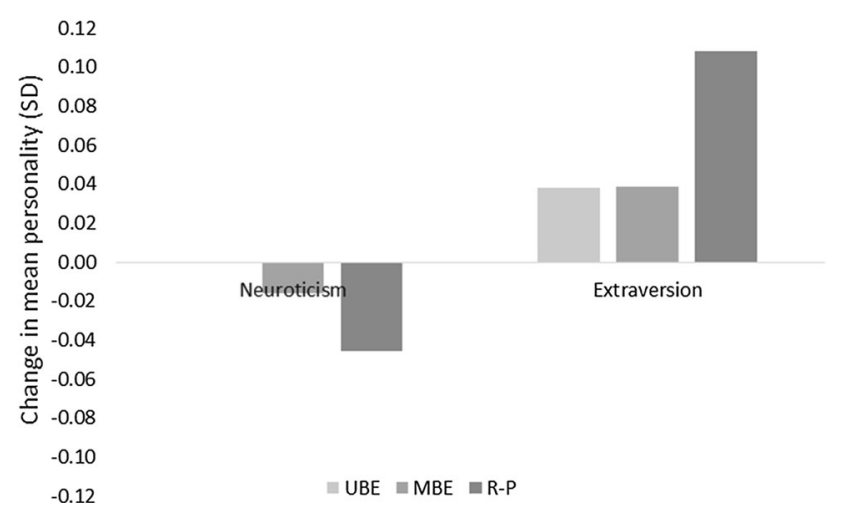

Fig. 1 Estimated selection responses. Estimated selection responses of the two personality traits, by univariate (UBE) and multivariate (MBE) breeder's equation and by the Robertson-Price identity (R-P) expected to decrease and the average extraversion to increase. In addition, we detected sex differences in the underlying genetic personality-fitness associations. These results generally reflect the phenotypic relationships found in previous studies, with extraversion being positively, and neuroticism negatively associated with number of children, and with some differences between the sexes (Berg et al. 2013, 2014; Dijkstra and Barelds 2009; Jokela et al. 2011; Jokela and Keltikangas-Järvinen 2009; Jokela et al. 2010). However, other factors may drive the average levels of extraversion and neuroticism in directions opposite to those implied by fertility differences. For example, levels of neuroticism and anxiety have been reported to increase in American birth cohorts born between the 1950s and 1990s (Twenge 2000). Future research should simultaneously assess the relative importance of genetic response to selection and observed change in personality across generations.

The univariate heritability estimates of the current sample were also in agreement with previous findings on the genetic basis of extraversion and neuroticism (Vukasovic and Bratko 2015). The heritability estimate of lifetime reproductive success is as well in line with previous findings in more recent Western cohorts, with heritability of various fitness measures being around $40 \%$, with no shared environmental effects - although this estimate varies greatly by cultural context (e.g., Kohler et al. 2006; Kosova et al. 2010). However, the phenotypic and genetic approaches to (micro) evolution in the present study yielded notably different results on the expected selection responses.

According to the most simple, but often used, univariate breeder's equation neuroticism was not subject to evolutionary change because phenotypically it was not associated with fitness in this population. The more precise multivariate form of the equation, however, yielded a selection response for neuroticism due to the fact that a genetically correlated trait (extraversion that is) was selected in men. Further, the prediction based on the Robertson-Price equation, suggested a stronger selection response than the phenotypic approach. Extraversion, on the other hand, was both phenotypically and genetically correlated with fitness. But with extraversion, the genotypic analyses yielded decidedly stronger estimates on the selection response than did the phenotypic analyses (see Fig. 1). These results warrant caution when making inferences on the evolution of personality in humans (and most likely in non-human animals, too) based on phenotypic data and analyses only. They suggest that some unmeasured traits or environmental factors affect both personality and fitness in ways that attenuate their phenotypic associations. The results also highlight the importance of investigating several inter-related personality traits and their 
covariance with each other simultaneously to predict responses to selection accurately, and studying selection in both sexes in order to quantify sexual conflict over personality characters and its importance for evolutionary processes.

Our data have several strengths for addressing the aims of our study. First, the study population is a modern secular society with widespread availability of contraceptives, which provides an optimal context to test the presence of natural selection in modern Western societies. Second, the reproductive data for this sample are highly accurate because they come from registry data, and are thus not affected by selective attrition of participants over the study follow-up period. Third, the structure of the twin data, and use of twin modelling thereof, allows for a more precise estimation of genetic covariances between traits and fitness than the approach based on breeding values (Bolund et al. 2011; Morrissey et al. 2010). Many previous attempts to examine whether phenotypic selection differentials have the potential to cause evolutionary change have used the approach based on breeding values (e.g., Kruuk et al. 2002). In addition, with twin data, genetic and environmental components can be separated more efficiently than in analyses of pedigree data ("animal models") generally used in evolutionary biology (Kruuk and Hadfield 2007).

Some methodological limitations of twin studies need to be considered, however. The phenotypic (co)variance patterns can arise due to many different kinds of genetic and environmental influences. To circumvent this problem, the classical twin model makes assumptions, and if these assumptions are violated, the estimates yielded will be biased (see e.g., Rijsdijk and Sham 2002). Firstly, there should be no assortative mating for the trait studied as this could inflate the estimates of shared environment $(C)$. This assumption seems to hold for personality (Bouchard and Loehlin 2001). Secondly, there should be no gene-environment interactions (genetic effects that are dependent on environment, and vice versa) or gene-environment correlations (genetic selection of individuals to specific environmental circumstances). Gene-shared environmental correlations tend to mimic shared environmental effects (C), and gene-non-shared environmental correlations tend to mimic genetic effects (A) (Purcell 2002). Gene-shared environmental interactions, in turn, mimic A, and genenon-shared interactions mimic E (Purcell 2002). Without measured environmental influences, these effects are very difficult, if not impossible, to be disentangled (Rijsdijk and Sham 2002). These assumptions may be more problematic in respect to personality traits. For example, gene-environment interactions have been reported in some studies of personality (Badcock et al. 2011; Reiner and Spangler 2011). Thus, it is impossible to say, with the data at hand, whether such influences inflate the effect of unique environment and underestimate the genetic covariance between personality and $w$, or vice versa. It might be that the relatively large point estimate of the genetic covariance between neuroticism and $w$ in women, with the upper limit of the $95 \%$ confidence interval just slightly above zero (see Table 4), could be a sign of a true (negative) genetic covariance between neuroticism and $w$, which was just not statistically significantly picked up by our data and methods at use. Replicative studies on this subject on other human and non-human samples will hopefully shed more light on this matter.

Besides estimates of genetic correlations, the twin analysis yielded estimates of environmental correlations between the two personality traits and $w$. In this study, the associations between personality traits and lifetime reproductive success were not environmentally mediated. The presence of genetic covariance between personality and $w$ with the absence of environmental covariance between the two is surprising, to say the least. Our results suggest that it is not neurotic or extraverted behavior per se that leads to differences in fertility, but the genetics underlying the personality differences. This is somewhat counterintuitive because personality traits are associated with reproductive behavior. For example, extraversion and related personality traits are associated with higher number of sexual partners (Nettle 2005), sexual risk behaviors such as lack of contraception (Hoyle et al. 2000), and a higher risk of unplanned pregnancies (Berg et al. 2013). Neuroticism, on the other hand, is known to be an undesirable trait in a potential mate (Stone et al. 2012). High neuroticism also seems to be associated with higher ambivalence regarding the wish to have children (Pinquart et al. 2008). According to our results, only insofar as these behavioral tendencies are manifestations of the underlying genetic variation, they will be associated with lifetime reproductive success.

Another way of expressing our findings is that personality as a behavioral tendency is not being selected, but something covarying genetically with personality is. Genetic covariances can emerge due to pleiotropic effects (a gene has multiple effects on more than one trait) or linkage disequilibrium (different genes are located close to each other in a chromosome and therefore tend to be inherited together) (Falconer and Mackay 1996). The associations between personality and fertility might therefore be mediated by common biological factors that underlie personality variation and reproductive functions, regardless of behavior. In the case of extraversion and lifetime reproductive success in men, testosterone-the main male sex hormone-and extraversion seem to be correlated (Alvergne et al. 2010b). In women, there is some evidence that higher neuroticism might be associated with lower estrogen levels (Ziomkiewics et al. 2012). However, the evidence for common biological factors explaining the 
genetic covariance between personality traits and fertility is too limited to be evaluated more comprehensively, and further studies are needed on the mechanisms explaining such associations both in humans and other species.

The differences in the phenotypic and genetic approaches to selection response, and the presence of genetic covariance with the lack of environmental covariance between personality and fitness provide important empirical evidence for evolutionary hypotheses on personality (e.g., Penke et al. 2007). On one hand, our results show that personality is visible to selection, and can be expected to evolve in response to selection. Even though the effects of personality on fitness are small, even very weak natural selection will have substantial evolutionary consequences, especially if the selective pressures remain the same over time (see e.g., Penke et al. 2007).

One recent study using genome wide single nucleotide data assessed the genetic variance structure in Cloninger's temperamental traits and came to the conclusion that mutation-selection balance is the most probable mechanism maintaining genetic variance in those traits (Verweij et al. 2012). Our results on extraversion are in line with this hypothesis. In addition, based on our results, sexual selection and differential mate preferences for men and women (Schuett et al. 2010) are conceivable candidates for evolutionary mechanisms, because the effects of these traits were different in men and women (see also Alvergne et al. 2010a). Balancing selection through environmental heterogeneity (Penke et al. 2007) is another possible explanation because it seems that environmental conditions can cause fluctuation in the fitness consequences of personality in humans and other animals (see also Penke and Jokela 2016; for studies on non-human animals see e.g., Dingemanse et al. 2004; Reale and Festa-Bianchet 2003). For example, high novelty seeking (a trait that correlates with extraversion) increased the probability of having children only in those not living with a partner in a previous study on a Finnish sample (Jokela et al. 2010), and high neuroticism increased rather than decreased offspring number in rural Senegalese women (Alvergne et al. 2010a). Finally, we did not find evidence of stabilizing or disruptive selection, as the associations between personality traits and lifetime reproductive success were linear.

On the other hand, our results raise the question of whether it is actually personality differences in behavior at all that is the evolutionarily relevant aspect of personality. It seems that researchers interested in the origins and evolution of personality should delve deeper into the genetic correlates of personality, such as reproductive hormonal functioning mentioned above. Most importantly, since, to our best knowledge, this is the first study examining the underlying genetics in the phenotypic associations between personality and fitness, more studies on this matter are needed. For example, the genetic covariance between extraversion and fitness found in this contemporary industrialized population is not informative about the evolutionary past. It remains to be seen whether similar genetic covariances are observed in other human populations and in non-human animals.

In conclusion, the results of our study provide the first quantitative genetic evidence of the associations between personality and fitness in humans or other animals. The data were from a large population-based sample with a long follow-up period and detailed fertility history information covering practically the complete reproductive age of the participants. The differences between the phenotypic and genetic approach found in this study suggest that studies relying only on phenotypic data may lead not only to misestimation of the magnitude of selection responses, but to misleading hypotheses on the evolution of and evolutionary forces working on personality.

\section{Compliance with Ethical Standards}

Conflict of Interest Venla Berg, Virpi Lummaa, Ian J. Rickard, Karri Silventoinen, Jaakko Kaprio and Markus Jokela declare that they have no conflict of interest.

Human and Animal Rights and Informed Consent All procedures performed in this study involving human participants were in accordance with the ethical standards of the institutional and/or national research committee and with the 1964 Helsinki declaration and its later amendments or comparable ethical standards. Informed consent was obtained from all individual participants included in the study.

Funding This study was funded by the Kone Foundation, University of Helsinki Research Funds, the Academy of Finland (grant number 266898 for VB, grant number 263278 for JK, grant number 292368 for VL, and grant number 266592 for KS), Wissenschaftskolleg zu Berlin, and the Royal Society.

\section{Appendix 1}

Items for extraversion and neuroticism, as translated in Tarkkonen et al. 1981

Extraversion

1. Do you like to have a lot of things going on around you?

2. Do you almost always have an answer ready when spoken to?

3. Do you prefer to keep to the background in the company of people?

4. Do you regard yourself as happy and carefree?

5. Do you have a lively manner?

6. Can you quickly describe your thoughts in words?

7. Do you have anything against selling things or asking people for money for some charitable purpose? 
8. Do you keep things to yourself except with good friends?

9. Do you like to crack jokes and tell funny stories to your friends?

\section{Neuroticism}

1. Are you often uneasy, feeling that there is something you want without knowing it?

2. Are you sometimes happy or sometimes sad without any special reason?

3. Do you often reach decisions too late?

4. Do you often feel tired or listless without any special reason?

5. Are you often lost in your thoughts?

6. Are you extremely sensitive in any respects?

7. Are you ever too restless to sit still?

8. Do you have difficulties in falling asleep?

9. Do you have nervous problems?

10. Do you usually worry a long time after a distressing incident?

\section{References}

Alvergne A, Jokela M, Lummaa V (2010a) Personality and reproductive success in a high-fertility human population. Proc Natl Acad Sci USA 107:11745-11750

Alvergne A, Jokela M, Faurie C, Lummaa V (2010b) Personality and testosterone in men from a high-fertility population. Personal Individ Differ 49:840-844

Badcock PB, Moore E, Williamson E, Berk M, Williams LJ, Bjerkeset O, Nordahl HM, Patton GC, Olsson CA (2011) Modeling gene-environment interaction in longitudinal data: risk for neuroticism due to interaction between maternal care and the dopamine 4 receptor gene (DRD4). Aust J Psychol 63:18-25

Berg V, Rotkirch A, Väisänen H, Jokela M (2013) Personality is differentially associated with planned and non-planned pregnancies. J Res Personal 47:296-305

Berg V, Lummaa V, Lahdenperä M, Rotkirch A, Jokela M (2014) Personality and long-term reproductive success measured by the number of grandchildren. Evol and Hum Behav 35:533-539

Bolund E, Schielzeth H, Forstmeier W (2011) Correlates of male fitness in captive zebra finches-a comparison of methods to disentangle genetic and environmental effects. BMC Evol Biol $11: 327$

Bouchard TJ, Loehlin JC (2001) Genes, evolution, and personality. Behav Genet 31:243-273

Briley DA, Harden KP, Tucker-Drob EM (2015) Genotype $\times$ cohort interaction on completed fertility and age at first birth. Behav Genet 45:71-83

Charmantier A, Garant D (2005) Environmental quality and evolutionary potential: lessons from wild populations. Proc R Soc B Biol Sci 272:1415-1425

Dijkstra P, Barelds DPH (2009) Women's well-being: the role of individual differences. Scand J Psychol 50:309-315

Dingemanse NJ, Réale D (2005) Natural selection and animal personality. Behaviour 142:1159-1184

Dingemanse NJ, Wolf M (2010) Recent models for adaptive personality differences: a review. Philos Trans R Soc Lond B Biol Sci 365:3947-3958
Dingemanse NJ, Both C, Drent PJ, Tinbergen JM (2004) Fitness consequences of avian personalities in a fluctuating environment. Proc R Soc B Biol Sci 271:847-852

Dochtermann NA, Roff DA (2010) Applying a quantitative genetics framework to behavioural syndrome research. Philos Trans $\mathrm{R}$ Soc Lond B Biol Sci 365:4013-4020

Eaves LJ, Martin NG, Heath AC, Hewitt JK, Neale MC (1990) Personality and reproductive fitness. Behav Gen 20:563-568

Efron B, Tibshirani RJ (1993) An Introduction to the Bootstrap. Chapman \& Hall/CRC, Boca Raton

Eyre-Walker A, Keightley PD (2007) The distribution of fitness effects of new mutations. Nat Rev Genet 8:610-618

Eysenck, H. J. (1967). The biological basis of personality, vol 689 Transaction publishers

Falconer DS, Mackay TFC (1996) Introduction to Quantitative Genetics, 4th edn. Pearson Education Ltd, Harlow

Fisher RA (1930) The genetical theory of natural selection: a complete variorum edition. Oxford University Press, Oxford

Floderus B (1974) Psycho-social factors in relation to coronary heart disease and associated risk factors. Nordisk Hygienisk Tidskrift (Suppl 6)

Goodman A, Koupil I (2009) Social and biological determinants of reproductive success in Swedish males and females born 1915-1929. Evol Hum Behav 30:329-341

Gosling SD (2001) From mice to men: what can we learn about personality from animal research? Psychol Bull 127:45

Hill WG (2014) Applications of population genetics to animal breeding, from Wright, Fisher and Lush to genomic prediction. Genetics 196:1-16

Hoyle RH, Fejfar MC, Miller JD (2000) Personality and sexual risk taking: a quantitative review. J Personal 68:1203-1231

Jokela M (2012) Birth-cohort effects in the association between personality and fertility. Psych Sci 23:835-841

Jokela M, Keltikangas-Järvinen L (2009) Adolescent leadership and adulthood fertility: revisiting the "central theoretical problem of human sociobiology". J Personal 77:213-230

Jokela M, Kivimäki M, Elovainio M, Keltikangas-Järvinen L (2009) Personality and Having children: a two-way relationship. J Personal Soc Psychol 96:218-230

Jokela M, Hintsa T, Hintsanen M, Keltikangas-Järvinen L (2010) Adult temperament and childbearing over the life course. Eur J Pers 24:151-166

Jokela M, Alvergne A, Pollet TV, Lummaa V (2011) Reproductive behavior and personality traits of the five factor model. Eur $\mathrm{J}$ Personal 25:487-500

Kaprio J, Koskenvuo M (2002) Genetic and environmental factors in complex diseases: the older Finnish twin cohort. Twin Res 5:358-365

Kartiovaara L, Säkkinen S (2007) Lasten muualla asuvat vanhemmat [The absent parents of children]. Suomalainen lapsi 2007 [The Finnish Child 2007]. Tilastokeskus \& Stakes, Helsinki, pp 109-127

Kline RB (2005) Principles and Practice of Structural Equation Modeling. The Guildford Press, New York

Kohler HP, Rodgers JL, Christensen K (1999) Is fertility behavior in our genes? Findings from a Danish twin study. Popul Dev Rev 25:253-288

Kohler HP, Rodgers JL, Miller WB, Skytthe A, Christensen K (2006) Bio-social determinants of fertility. Int J Androl 29:46-53

Kosova G, Abney M, Ober C (2010) Heritability of reproductive fitness traits in a human population. Proc Natl Acad Sci U S A 107:1772-1778

Kruuk LEB, Hadfield JD (2007) How to separate genetic and environmental causes of similarity between relatives. J Evol Biol 20:1890-1903 
Kruuk LEB, Slate J, Pemberton JM, Brotherstone S, Guinness F, Clutton-Brock T (2002) Antler size in red deer: heritability and selection but no evolution. Evolution 56:1683-1695

Lande R, Arnold SJ (1983) The measurement of selection on correlated characters. Evolution 37:1210-1226

Merilä J, Sheldon BC (1999) Genetic architecture of fitness and nonfitness traits: empirical patterns and development of ideas. Heredity 83:103-109

Merilä J, Kruuk L, Sheldon B (2001a) Cryptic evolution in a wild bird population. Nature 412:76-79

Merilä J, Sheldon B, Kruuk L (2001b) Explaining stasis: microevolutionary studies in natural populations. Genetica 112:199-222

Miller WB, Bard DE, Pasta DJ, Rodgers JL (2010) Biodemographic modeling of the links between fertility motivation and fertility outcomes in the NLSY79. Demography 47:393-414

Morrissey M, Kruuk L, Wilson A (2010) The danger of applying the breeder's equation in observational studies of natural populations. J Evol Biol 23:2277-2288

Neale MC, Maes HHM (2003) Methodology for Genetic Studies of Twins and Families. Kluwer, Academic Publishers B. V, Dordrecht, The Netherlands

Nettle D (2005) An evolutionary approach to the extraversion continuum. Evol Hum Behav 26:363-373

Penke L, Jokela M (2016) The evolutionary genetics of personality revisited. Curr Opin Psychol 7:104-109

Penke L, Denissen JJA, Miller GF (2007) The evolutionary genetics of personality. Eur J Personal 21:549-587

Pettay JE, Kruuk LEB, Jokela J, Lummaa V (2005) Heritability and genetic constraints of life-history trait evolution in preindustrial humans. Proc Natl Acad Sci USA 102:2838-2843

Pinquart M, Stotzka C, Silbereisen RK (2008) Personality and ambivalence in decisions about becoming parents. Soc Behav Personal 36:87-95

Pitkänen K, Jalovaara M (2007) Perheet ja perheenmuodostus [Families and family formation]. In: Koskinen S, Martelin T, Notkola I-L, Notkola V, Pitkänen K, Jalovaara M, Mäenpää E, Ruokolainen A, Ryynänen M, Söderling I (eds) Suomen väestö [The population of Finland], 2nd edn. Gaudeamus Helsinki University Press, Tampere, pp 115-167

Purcell S (2002) Variance components models for gene-environment interaction in twin analysis. Twin Res 5:554-571

Rausher MD (1992) The measurement of selection on quantitative traits: biases due to environmental covariances between traits and fitness. Evolution: 616-626

Reale D, Festa-Bianchet M (2003) Predator-induced natural selection on temperament in bighorn ewes. Anim Behav 65:463-470

Reiner I, Spangler G (2011) Dopamine D4 receptor exon III polymorphism, adverse life events and personality traits in a nonclinical german adult sample. Neuropsychobiology 63:52-58

Reis O, Doernte M, von der Lippe H (2011) Neuroticism, social support, and the timing of first parenthood: a prospective study. Personal Individ Differ 50:381-386

Rijsdijk FV, Sham PC (2002) Analytic approaches to twin data using structural equation models. Brief Bioinform 3:119-133

Rose RJ, Kaprio J, Koskenvuo M (1988a) Genetic contributions to behavioral consistency and change-data from a 6-year followup of the Finnish twin cohort. Behav Genet 18:730

Rose RJ, Koskenvuo M, Kaprio J, Sarna S, Langinvainio H (1988b) Shared genes, shared experiences, and similarity of personality-data from 14,288 adult Finnish co-twins. J Personal Soc Psychol 54:161-171
Ruokolainen A, Notkola I- (2007) Hedelmällisyys [Fertility]. In: Koskinen S, Martelin T, Notkola I-L, Notkola V, Pitkänen K, Jalovaara M, Mäenpää E, Ruokolainen A, Ryynänen M, Söderling I (eds) Suomen väestö [The population of Finland], 2nd edn. Gaudeamus Helsinki University Press, Tampere, pp 77-113

Sarna S, Kaprio J, Sistonen P, Koskenvuo M (1978) Diagnosis of twin zygosity by mailed questionnaire. Hum Hered 28:241-254

Schuett W, Tregenza T, Dall SRX (2010) Sexual selection and animal personality. Biol Rev 85:217-246

Sih A, Bell A, Johnson JC (2004) Behavioral syndromes: an ecological and evolutionary overview. Trends Ecol Evol 19:372-378

Smith BR, Blumstein DT (2008) Fitness consequences of personality: a meta-analysis. Behav Ecol 19:448-455

Stone EA, Shackelford TK, Buss DM (2012) Is variability in mate choice similar for intelligence and personality traits? Testing a hypothesis about the evolutionary genetics of personality. Intelligence 40:33-37

Tarkkonen L, Koskenvuo M, Kaprio J, Langinvainio H, FloderusMyrhed B (1981) Crossvalidation of the Eysenck extroversion and neuroticism scales in Finland and Sweden. Kansanterveystieteen julkaisuja M 62:1981

Twenge JM (2000) The age of anxiety? The birth cohort change in anxiety and neuroticism, 1952-1993. J Personal Soc Psychol 79:1007-1021

van Oers K, Sinn DL (2011) Toward a basis for the phenotypic gambit: Advances in the evolutionary genetics of animal personality. In: Inoue-Murayama M, Kawamura S, Weiss A (eds) From Genes to Animal Behavior. Springer, Japan, pp $165-183$

van Oers K, de Jong G, van Noordwijk AJ, Kempenaers B, Drent PJ (2005) Contribution of genetics to the study of animal personalities: a review of case studies. Behaviour 142:1185-1206

Van Tienderen PH, De Jong G (1994) A general-model of the relation between phenotypic selection and genetic response. J Evol Biol $7: 1-12$

Verweij KJH, Yang J, Lahti J, Veijola J, Hintsanen M, Pulkki-Raback L, Heinonen K, Pouta A, Pesonen A, Widen E, Taanila A, Isohanni M, Miettunen J, Palotie A, Penke L, Service SK, Heath AC, Montgomery GW, Raitakari O, Kahonen M, Viikari J, Raikkonen K, Eriksson JG, Keltikangas-Jarvinen L, Lehtimaki T, Martin NG, Jarvelin M, Visscher PM, Keller MC, Zietsch BP (2012) Maintenance of genetic variation in human personality: testing evolutionary models by estimating heritability due to common causal variants and investigating the effect of distant inbreeding. Evolution 66:3238-3251

Vukasovic T, Bratko D (2015) Heritability of personality: a metaanalysis of behavior genetic studies. Psychol Bull 141:769-785

Williams RL (2000) A note on robust variance estimation for clustercorrelated data. Biometrics 56:645-646

Wolf M, McNamara JM (2012) On the evolution of personalities via frequency-dependent selection. Am Nat 179:679-692

Wolf J, Wade M (2001) On the assignment of fitness to parents and offspring: whose fitness is it and when does it matter? J Evol Biol 14:347-356

Ziomkiewicz A, Wichary S, Bochenek D, Pawlowski B, Jasienska G (2012) Temperament and ovarian reproductive hormones in women: evidence from a study during the entire menstrual cycle. Horm Behav 61:535-540 